\title{
Single-stage Acetabular Revision During Two-stage THA Revision for Infection is Effective in Selected Patients
}

\author{
Bernd Fink MD, Michael Schlumberger MD, Damian Oremek MD
}

Received: 14 October 2016/Accepted: 22 March 2017/Published online: 28 March 2017

(C) The Association of Bone and Joint Surgeons (B) 2017

\begin{abstract}
Background The treatment of periprosthetic infections of hip arthroplasties typically involves use of either a singleor two-stage (with implantation of a temporary spacer) revision surgery. In patients with severe acetabular bone deficiencies, either already present or after component removal, spacers cannot be safely implanted. In such hips where it is impossible to use spacers and yet a two-stage revision of the prosthetic stem is recommended, we have
\end{abstract}

Each author certifies that neither he, nor any member of his immediate family, have funding or commercial associations (consultancies, stock ownership, equity interest, patent/licensing arrangements, etc) that might pose a conflict of interest in connection with the submitted article.

All ICMJE Conflict of Interest Forms for authors and Clinical Orthopaedics and Related Research ${ }^{\circledR}$ editors and board members are on file with the publication and can be viewed on request.

Clinical Orthopaedics and Related Research ${ }^{\mathbb{R}}$ neither advocates nor endorses the use of any treatment, drug, or device. Readers are encouraged to always seek additional information, including FDAapproval status, of any drug or device prior to clinical use.

Each author certifies that his institution has approved the human protocol for this investigation, that all investigations were conducted in conformity with ethical principles of research, and that informed consent was obtained.

This work was performed at the Department of Joint Replacement, General and Rheumatic Orthopaedics, Orthopaedic Clinic Markgröningen gGmbH, Markgröningen, Germany.

B. Fink $(\bowtie)$, M. Schlumberger, D. Oremek

Department of Joint Replacement, General, and Rheumatic Orthopaedics, Orthopaedic Clinic Markgröningen gGmbH, Kurt-

Lindemann-Weg 10, 71706 Markgröningen, Germany

e-mail: b.fink@okm.de

B. Fink

Orthopaedic Department, University-Hospital Hamburg-

Eppendorf, Hamburg, Germany combined a two-stage revision of the stem with a single revision of the cup. To our knowledge, this approach has not been reported before.

Questions/purposes (1) What proportion of patients treated with single-stage acetabular reconstruction as part of a two-stage revision for an infected THA remain free from infection at 2 or more years? (2) What are the Harris hip scores after the first stage and at 2 years or more after the definitive reimplantation?

Methods Between June 2009 and June 2014, we treated all patients undergoing surgical treatment for an infected THA using a single-stage acetabular revision as part of a twostage THA exchange if the acetabular defect classification was Paprosky Types 2B, 2C, 3A, 3B, or pelvic discontinuity and a two-stage procedure was preferred for the femur. The procedure included removal of all components, joint débridement, definitive acetabular reconstruction (with a cage to bridge the defect, and a cemented socket), and a temporary cemented femoral component at the first stage; the second stage consisted of repeat joint and femoral débridement and exchange of the femoral component to a cementless device. During the period noted, 35 patients met those definitions and were treated with this approach. No patients were lost to followup before 2 years; mean followup was 42 months (range, 24-84 months). The clinical evaluation was performed with the Harris hip scores and resolution of infection was assessed by the absence of clinical signs of infection and a C-reactive protein level less than $10 \mathrm{mg} / \mathrm{L}$. All patients were assessed before surgery, between stages, every 3 months during the first year after surgery, every 6 months during the second year postoperative, and at latest followup, and were retrospectively drawn from a longitudinally maintained institutional database.

Results Thirty-four of 35 patients $(97.2 \%$; 95\% CI, $85.4 \%-99.5 \%$ ) appeared free of infection by criteria of 
Masri et al. and Zimmerli et al. at latest followup. The Harris hip score was $61 \pm 13$ points after the first operation and $82 \pm 16$ points 2 years after the second operation. Conclusions This technique is a promising treatment option for periprosthetic infections of the hip in which substantial acetabular defects exclude implantation of a normal spacer and a two-stage revision of the femoral component is favored.

Level of Evidence Level IV, therapeutic study.

\section{Introduction}

Periprosthetic infections occur in approximately $1 \%$ of patients, but are devastating $[10,36]$. Chronic infections generally are managed with prosthesis revision. Options for surgical treatment include a single-stage procedure, in which the definitive revision implant is placed, and a twostage revision, where mostly a temporary spacer is used [9]. A single procedure avoids the morbidity of repeat surgery, but at the cost of a higher risk of persistent or recurrent infection, even though success rates are reported between $75 \%$ and $100 \%$ for both concepts [10] (Table 1). However, two-stage septic revision surgery is still the gold standard [10].

Severe acetabular defects, either at initial presentation or those that occur after joint débridement and removal of the infected cup, can preclude the use of a temporary acetabular spacer. Protrusio acetabuli and hip instability are serious complications that occur in some patients in those scenarios. Solutions for such a problem may be a temporary Girdlestone hip procedure, a provisional cage, an antibiotic-loaded cement shelf, a nonarticulating spacer, or a one-stage procedure with cages. In situations where a two-stage procedure is preferred on the femoral side (for example, cementless reimplantation of the femoral stem after a transfemoral approach, or a substantially sclerotic femoral canal precluding use of a cemented stem) and substantial acetabular defects are present, we have started to use an approach in which the acetabulum undergoes definitive reconstruction at the initial stage. After thorough débridement of joint and acetabular bone, the acetabular defect is bridged with a cage and a polyethylene cup is cemented in place. On the femoral side, a prosthetic stem with recognized poor fixation characteristics is cemented in place as a spacer $[10,12,14]$. The latter then is removed during the second stage of the revision and replaced with a cementless stem. This revision concept, which combines a one-stage revision of the acetabular component and a two-stage revision of the femoral component, to the best of our knowledge, has not been reported before.

We therefore asked (1) What proportion of patients treated with single-stage acetabular reconstruction as part of a two-stage revision for an infected THA remain free from infection at 2 or more years? (2) What are the Harris hip scores after the first stage and at 2 years or more after the definitive reimplantation?

Table 1. Studies of septic one- and two-stage revisions with clinical results using the Harriship score

\begin{tabular}{|c|c|c|c|c|c|c|}
\hline Study & One- or two-stage revision & $\begin{array}{l}\text { Number of } \\
\text { patients }\end{array}$ & $\begin{array}{l}\text { Age (years) } \\
\text { Mean } \pm \text { SD (range) }\end{array}$ & $\begin{array}{l}\text { Followup } \\
\text { Mean } \pm \mathrm{SD} \\
\text { (range) }\end{array}$ & $\begin{array}{l}\text { Success } \\
\text { rate }\end{array}$ & $\begin{array}{l}\text { Harris hip score } \\
\text { Mean } \pm \text { SD (range) }\end{array}$ \\
\hline $\begin{array}{l}\text { Choi et al. } \\
\text { [7] }\end{array}$ & One-stage & 17 & $65(38-88)$ & $5(1-11)$ & $82 \%$ & $77 \pm 14(46-94)$ \\
\hline $\begin{array}{l}\text { De Man } \\
\text { et al. [9] }\end{array}$ & One-stage & 22 & $69(48-88)$ & $3.8 \pm 2.2$ & $100 \%$ & $84 \pm 17$ \\
\hline $\begin{array}{l}\text { Ilchmann } \\
\text { et al. [19] }\end{array}$ & One-stage & 39 & & $6.6(2-15.1)$ & $100 \%$ & $81(29-99)$ \\
\hline $\begin{array}{l}\text { Camurcu } \\
\text { et al. [5] }\end{array}$ & Two-stage & 41 & $62 \pm 14.1(28-87)$ & $4.5 \pm 1.9(2-8)$ & $95.1 \%$ & $81.8 \pm 5.8$ \\
\hline $\begin{array}{l}\text { Choi et al. } \\
\text { [7] }\end{array}$ & Two-stage & 44 & $65(38-88)$ & $5(1-11)$ & $75 \%$ & $60(7-100)$ \\
\hline \multirow[t]{2}{*}{$\begin{array}{l}\text { Citak et al. } \\
{[8]}\end{array}$} & \multirow[t]{2}{*}{$\begin{array}{l}\text { Two-stage, surgeon made versus } \\
\text { preformed spacers }\end{array}$} & 1027 & $\begin{array}{l}63.9 \pm 5.1(52.6- \\
73.9)\end{array}$ & $3.6(1.2-12)$ & $94 \%$ & $84.3(68-97.8)$ \\
\hline & & 604 & $\begin{array}{l}64.7 \pm 5.6(55.7- \\
\quad 71.8)\end{array}$ & $3.8(2.6-5.6)$ & $94.5 \%$ & $81.8(71.2-92.3)$ \\
\hline $\begin{array}{l}\text { De Man } \\
\text { et al. [9] }\end{array}$ & Two-stage & 50 & $70(40-88)$ & $4.9 \pm 3.6$ & $98 \%$ & $80 \pm 18$ \\
\hline $\begin{array}{l}\text { Hoberg et al. } \\
\text { [17] }\end{array}$ & Two-stage & 45 & $73.7(51-95)$ & $4.6(2-9.3)$ & $82.7 \%$ & $73.4(18-100)$ \\
\hline $\begin{array}{l}\text { Ibrahim } \\
\quad \text { et al. [18] }\end{array}$ & Two-stage & 125 & $68(42-78)$ & $8.6(5-13)$ & $96 \%$ & $81.2(33-98)$ \\
\hline
\end{tabular}


Table 2. The microorganisms identified as the cause of the periprosthetic infection

\begin{tabular}{ll}
\hline Microorganism & Number of infections \\
\hline Staphylococcus epidermidis & 8 \\
Propionibacterium acnes & 8 \\
Staphylococcus aureus & 6 \\
Staphylococcus capitis & 4 \\
Propionibacterium granulosum & 3 \\
Staphylococcus hominis & 2 \\
Streptococcus mitis/oralis & 2 \\
Enterococcus faecalis & 2 \\
Escherichia coli & 2 \\
Propionibacterium propionicum & 1 \\
Staphylococcus warneri & 1 \\
Staphylococcus saprophyticus & 1 \\
Candida albicans & 1 \\
Granulicatella adiacens & 1 \\
Actinomyces meyeri & 1 \\
Staphylococcus lugdunensis & 1 \\
Proteus mirabilis & 1 \\
Staphylococcus saccharolyticus & 1 \\
Listeria monocytogenes & 1 \\
\hline
\end{tabular}

\section{Patients and Methods}

Between June 2009 and June 2014, 225 patients with periprosthetic joint infections were treated. These patients consisted of 127 women and 98 men with a mean age of $68.3 \pm 16$ years, a mean BMI of $27 \pm 3 \mathrm{~kg} / \mathrm{m}^{2}$, and a median of the Charlson Comorbidity Index score of 0 (range, 0-2) [6]. Forty patients were treated with a onestage procedure and 150 with a standard two-stage procedure. For the remaining 35 patients for whom a two-stage procedure was preferred on the femoral side (necessity of a transfemoral approach and/or substantial sclerotic femoral canal), and had an acetabular defect of Paprosky Types 2B, 2C, 3A, 3B [3], or pelvic discontinuity, (classified intraoperatively after removal of the infected cup), we used a combination of one-stage acetabular and two-stage femoral revision. These 35 patients were examined in a retrospective study that used a longitudinally maintained institutional database for hip scores and infection-related endpoints. The minimum followup was 2 years $(42 \pm 17$ months; range, 24-84 months). No patients were lost to followup. One patient died 5 years after surgery from unrelated causes. The patient cohort consisted of 18 women and 17 men with a mean age of $70 \pm 15$ years, a mean BMI of $28 \pm 3 \mathrm{~kg} /$ $\mathrm{m}^{2}$, and a median Charlson Comorbidity Index score of 0 (range, $0-2$ ). The original diagnosis that led to the primary arthroplasty was osteoarthritis in 28 patients, femoral head fracture in two patients, femoral head necrosis in two patients, and rheumatoid arthritis in three patients. There were six cemented and 29 cementless acetabular cups and 10 cemented stems (three revision stems) and 25 cementless stems (eight revision stems). The lifespan of the primary implant was a median of 7 years (range, $0.2-24$ years). In 13 patients a primary implant was involved, but there also were nine patients who already had undergone one revision operation. Six patients previously had undergone two revision operations, three patients had three operations, three patients had four operations, and one patient had five operations. Eleven of the patients who had more than two operations underwent septic revision surgery at other hospitals. The distribution of diagnoses and prior procedures were not different in the study group compared with the whole group of patients with periprosthetic joint infections during the same period.

Periprosthetic infection was diagnosed according to the criteria of the Musculoskeletal Infection Society [28]. Preoperative aspiration of the hip was performed; this is a standard procedure in our clinic before any revision of a hip prosthesis is done and bacteriologic cultivation of the aspirated fluid is assessed for 14 days according to Schäfer et al. [30]. Bacteriologic and histologic examinations according to the methods of Atkins et al. [1], Virolainen et al. [35], and Pandey et al. [26] of the membrane at the site of loosening, which was removed during the operation, were performed to confirm the original diagnosis. The most frequent microorganisms detected by these methods were Staphylococcus epidermidis and Propionibacterium acnes (Table 2); two causative organisms were identified in seven patients and three in three patients.

The acetabular defects were classified intraoperatively according to the system reported by Bradford and Paprosky [3] as follows: 10 with Type $2 \mathrm{~B}$, seven with Type $2 \mathrm{C}$, seven with Type $3 \mathrm{~A}$, seven with Type $3 \mathrm{~B}$, and four with pelvic discontinuities. The femoral defects present before removal of the stem were classified according to Paprosky et al. [27] as follows: two with Type 1, 11 with Type 2, 14 with Type 3A, five with Type 3B, and three with Type 4. The femoral component was removed via a transfemoral approach (27 times) when the cementless stem was fully integrated in the bone or the cement mantle was tightly embedded (Fig. 1A-B); this procedure resulted in Type 3A bone defects in all the patients with preexisting Type 1 defects and in six patients with preexisting Type 2 defects.

The transfemoral approach was performed using a modified Wagner technique [11, 13, 14]. After removal of all implants and débridement, the cup was replaced as follows: 17 with a Ganz ring with a Müller ${ }^{\circledR}$ Low Profile Cup (Zimmer Biomet GmbH, Winterthur, Switzerland) (Fig. 1B), seven with a Burch-Schneider Reinforcement Cage with a Müller ${ }^{\circledR}$ Low Profile Cup (Zimmer Biomet 
Fig. 1A-D (A) The radiograph shows the pelvis of a 67-yearold patient with an infected THA implant on the left side, with a well-osseointegrated acetabular cup and a stable distal cement plug of a cemented stem after two-stage revision 1 year before. (B) A radiograph of the left hip obtained after the first operation shows a Ganz ring and the Müller ${ }^{\circledR}$ low-profile cup on the acetabular side and the femoral spacer implanted via a transfemoral approach. (C) This radiograph of the patient's pelvis obtained 2 weeks after the second operation shows the reimplanted femoral revision stem. (D) A radiograph obtained 2 years after the second operation shows osseointegration of the revision stem.
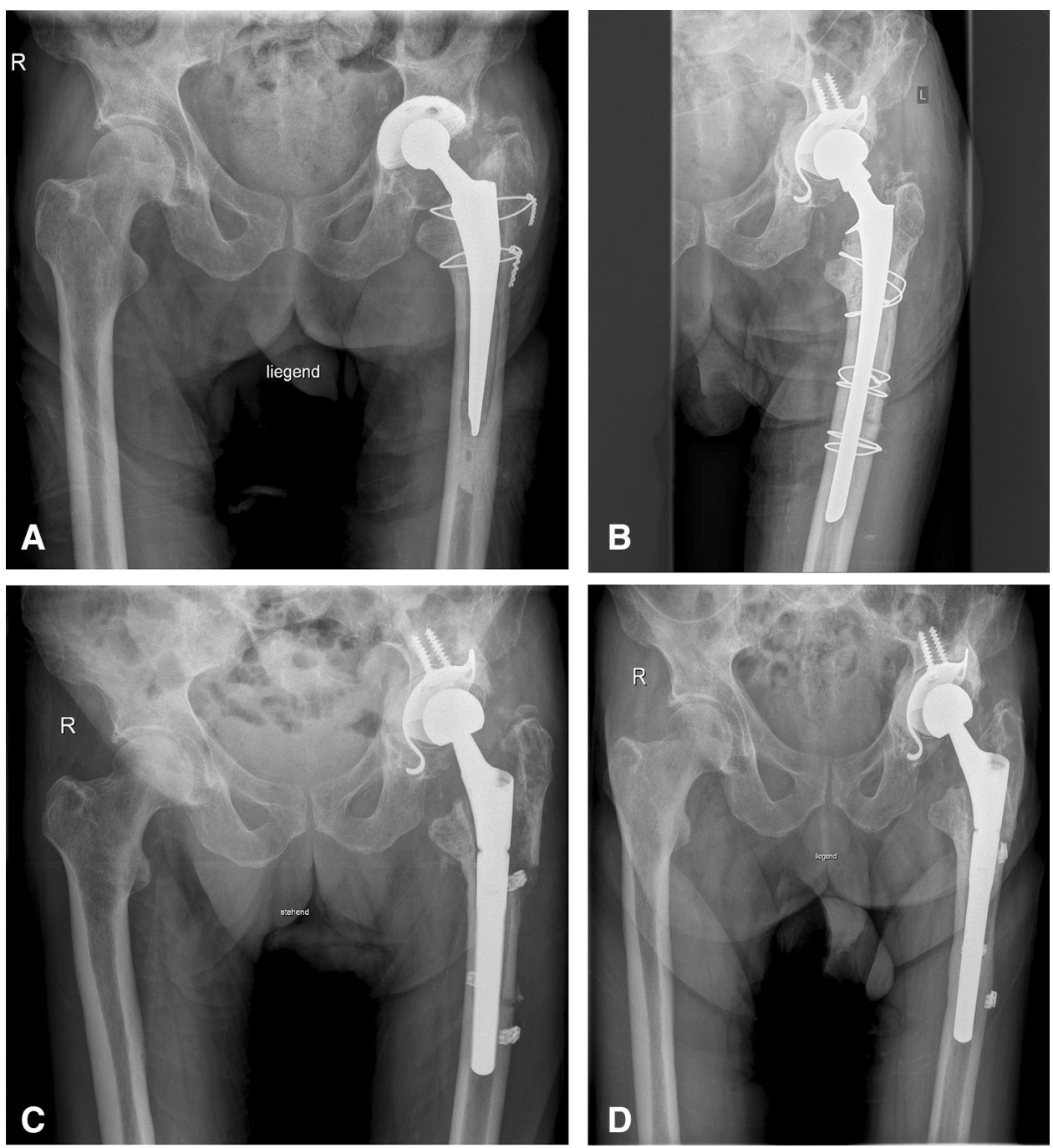

GmbH), six with a Trabecular Metal ${ }^{\mathrm{TM}}$ Acetabular Revision System (TMARS) with augments and a revision cup (Zimmer Biomet $\mathrm{GmbH}$ ), and five with a cup-and-cage system (Zimmer Biomet GmbH) (Table 3). For stems, we typically used obsolete monoblock implants that no longer are used for primary implantation. These stems are encased in antibiotic-containing cement and coated in the patient's blood to facilitate easier removal. If a transfemoral approach had been used, the bony flap was closed immediately after the cement-covered stem had been inserted with double cerclage wires $(1.5 \mathrm{~mm}$ diameter) and the excess cement removed from the flap. The two components of the spacer were connected by a metal head (Fig. 1B).

According to the antibiotic susceptibility profile of the microorganisms, a specific mixture of antibiotics was recommended by our microbiologist (LF) for use in the cement of the cup, the femoral spacer, and in systemic treatment (Table 4). A maximum of $10 \%$ of the total cement powder amount was added as antibiotic to the industrially prepared Palacos ${ }^{\circledR} \mathrm{G}$ (four times) (Heraeus Medical, Darmstadt, Germany) and Copal ${ }^{\mathbb{R}}$ cement (31 times) (Heraeus Medical); for example, $2 \mathrm{~g}$ vancomycin powder to the powder of $40 \mathrm{~g} \mathrm{Copal}{ }^{\circledR}$ cement. For 11 patients, the cement of the spacer contained two antibiotics and for 24 patients, the cement contained three antibiotics (Table 4). The parenteral antibiotic therapy was designed specifically for each patient by our microbiologist and was given for 2 weeks followed by individual oral administration of the antibiotic for 4 weeks (Table 4). Eleven patients received two antibiotics systemically, three received three antibiotics systemically, and one patient received four antibiotics systemically. Fourteen patients received two antibiotics orally.

Six weeks after removal of the infected implant (if the C-reactive protein was decreased to a level below $20 \mathrm{mg} / \mathrm{L}$ $[12,15])$, the femoral spacer was changed to a cementless standard stem in eight patients and a modular cementless revision stem $\left(\right.$ Revitan ${ }^{\circledR}$ curved; Zimmer $\mathrm{GmbH}$, 
Table 3. Distribution of the devices used in the different acetabular defects

\begin{tabular}{|c|c|c|c|c|c|c|}
\hline Device & Defect 2B & Defect $2 \mathrm{C}$ & Defect $3 \mathrm{~A}$ & Defect 3B & Pelvic discontinuity & Total \\
\hline Ganz-cage & 10 & 7 & & & & 17 \\
\hline Burch-Schneider-cage & & & 7 & & & 7 \\
\hline TMARS & & & & 6 & & 6 \\
\hline Cup-and-cage & & & & 1 & 4 & 5 \\
\hline Total & 10 & 7 & 7 & 7 & 4 & 35 \\
\hline
\end{tabular}

Table 4. Local and systemic antibiotic therapy

\begin{tabular}{|c|c|c|c|}
\hline Antibiotic & $\begin{array}{l}\text { Number of patients receiving local } \\
\text { antibiotics }\end{array}$ & $\begin{array}{l}\text { Number of patients receiving intravenous } \\
\text { antibiotics }\end{array}$ & $\begin{array}{l}\text { Number of patients receiving oral } \\
\text { antibiotics }\end{array}$ \\
\hline Vancomycin & 24 & 12 & \\
\hline Rifampicin & & 8 & 13 \\
\hline Gentamicin & 35 & & \\
\hline Clindamycin & 31 & & 1 \\
\hline Ampicillin + sulbactam & & 11 & \\
\hline Imipenem & & 6 & \\
\hline Penicillin G & & 5 & \\
\hline Flucloxacillin & & 4 & \\
\hline Meropenem & 3 & 2 & \\
\hline Fosfomycin & & 1 & \\
\hline Fluconazole & & 1 & 1 \\
\hline Ceftriaxon & & 1 & \\
\hline Ciprofloxacin & & 1 & 1 \\
\hline Cefuroxim & & 1 & \\
\hline Piperacillin + tazobactam & & 1 & \\
\hline Moxifloxacin & & 1 & \\
\hline Amoxicillin & & & 12 \\
\hline Levofloxacin & & & 10 \\
\hline Cotrimoxazole & & & 4 \\
\hline $\begin{array}{l}\text { Amoxicillin }+ \text { clavolanic } \\
\text { acid }\end{array}$ & & & 3 \\
\hline Fusidic acid & & & 1 \\
\hline Ampicillin & & & 1 \\
\hline Linezolid & & & 1 \\
\hline
\end{tabular}

Winterthur, Switzerland) in 27 patients (Fig. 1C). After implantation of the new prosthetic components, the transfemoral approach was closed again using new $1.5-\mathrm{mm}$ double cerclage wires in 26 patients and polyethylene cerclages in one patient (Fig. 1C-D).

During the reimplantation, at least five tissue samples were removed for bacteriologic examination and then the same parenteral antibiotic therapy was reinitiated as after the first stage. This was continued for 2 weeks and then changed to the appropriate oral administration of the antibiotic for 4 weeks. Rifampicin and ciprofloxacin were administered orally from the second day after both surgeries.
Postoperatively, we limited weightbearing to approximately 10 to $20 \mathrm{~kg}$ for 6 weeks. We increased this gradually to full weightbearing at 3 months postoperatively as described by others for other cementless revision stems [2, 32, 34].

All patients were examined before surgery and then at 3 months, 6 months, 9 months, 1 year, 18 months, and 2 years after surgery, and at the latest followup. Inflammatory parameters (C-reactive protein) also were followed. According to Masri et al. [24] and Zimmerli et al. [37], a patient could be judged infection-free at followup if he or she was free of clinical signs for infection (fever, local 
pain, redness, warmth, sinus tract infection) and had a Creactive protein level less than $10 \mathrm{mg} / \mathrm{L}$. The clinical outcome was evaluated by two of the authors (MS and DO) using the Harris hip score [16, 20].

The statistical analyses were conducted using SPSS for Windows Version 11.0 (SPSS Inc, Chicago, IL, USA). All subjects gave informed consent to participate in the study and the protocol was approved by the research ethics boards of the respective institutions.

\section{Results}

Thirty-four of 35 patients (97.2\%; 95\% CI, 85.4\%-99.5\%) were free of infection based on the criteria of Masri et al. [24] and Zimmerli et al. [37], at latest followup. There was a recurrence of infection in one patient 20 months after the second operation. This patient previously had three septic revision operations performed elsewhere, had infections with three different microorganisms ( $S$ epidermidis, Escherichia coli, and Proteus mirabilis), and had reinfection with $S$ epidermidis and $S$ lugdunensis. None of the samples taken during the second operation were positive for bacterial infection in any patients in this series.

The Harris hip score improved from $45 \pm 20$ (range, 582 ) points before surgery ( 35 patients) to $61 \pm 13$ (range, 20-74) with the spacer before the second operation (35 patients). All patients could walk pain-free with partial weightbearing. After the second operation, the Harris hip score increased steadily during the followup period: it was $65 \pm 12$ (range, 40-80) points at 3 months postoperative (35 patients), $68 \pm 14$ (range, 41-90) points 6 months postoperative (32 patients), $70 \pm 15$ (range, 46-92) points 9 months postoperative (31 patients), $74 \pm 15$ (range, 4692) points 12 months postoperative (34 patients), $79 \pm 16$ (range, 48-94) points 18 months postoperative (32 patients), and $82 \pm 16$ (range, 59-98) points 24 months postoperative (35 patients).

Two patients experienced dislocations; one after the first stage and one after stem reimplantation; both patients were treated conservatively. One patient had deep vein thrombosis. No other complications occurred. Mean blood loss was $1390 \pm 680 \mathrm{~mL}$ (range, 300-3600 mL) during the first operation and $1256 \pm 612 \mathrm{~mL}$ (range, 400-3200 mL) during the second.

\section{Discussion}

Severe acetabular defects can preclude the use of a temporary acetabular spacer in two-stage revisions of periprosthetic infections of hip arthroplasties. To address this, we have started to combine a one-stage revision of the acetabular component and a two-stage revision of the femoral component in selected patients. To the best of our knowledge, this concept has not been reported before. We therefore sought to assess freedom from infection and Harris hip scores after the first stage and at 2 years after the definitive reimplantation. Ninety-seven percent of our patients were infection free and had a Harris hip score of $61 \pm 13$ points after the first operation and $82 \pm 16$ points 2 years after the second operation.

The study has limitations, however. One is the relatively low number of patients. This is the first description of the method to be published and therefore can be regarded as being equivalent to a pilot study. The promising results will have to be confirmed in additional studies with greater numbers of patients. Another limitation is the relatively short followup. However, we suggest that a minimum of 2 years is sufficient for questions posed by the current study because reinfection occurs only rarely after 2 years of reimplantation [21, 24, 33]. However, the observation period does not permit any assessment of the lifespan of the implants used in the study. Moreover, we acknowledge the possibility of bias in patient selection. In general, we prefer to use an uncemented femoral stem for all revisions, including those for sepsis. We performed single-stage femoral revisions in selected hips where a susceptible organism was identified before surgery, and where adequate bone stock was available for a cemented stem but inadequate bone stock on the acetabular side for a spacer. With respect to the acetabulum, we selected a one-stage procedure in the presence of defects classified as Paprosky Type 2B or higher, because of the high risk of dislocation of standard spacers. This approach was chosen before surgery if the defects could be classified as Paprosky Types $3 \mathrm{~A}, 3 \mathrm{~B}$, or pelvic discontinuity preoperatively on radiographs and CT scans. If Paprosky Types 2B and 2C defects were found intraoperatively owing to the removal of wellfixed infected cups, and dislocation was likely, we opted for the one-stage procedure on the acetabular side. As such, we believe that any bias in selection is the use of this approach in more-difficult clinical settings.

We achieved a 97\% success rate with this concept, comparable to the results with standard two-stage revision surgery with success rates of $90 \%$ or more and standard one-stage revision with success rates between 80 and $100 \%$ [4, 10, 12] (Table 1). Lange et al. [22] calculated, in a meta-analysis, a risk of reinfection of $10.4 \%$ for two-stage and $13.1 \%$ for one-stage septic revision.

After the first operation, all patients could walk pain free with partial weightbearing and attained a mean Harris hip score of 61. Although we did not explicitly set out to compare our approach with a Girdlestone resection arthroplasty, we note that it represents a potential alternative in settings where a temporary Girdlestone might be 
used, where segmental acetabular defects make a standard two-stage septic revision with a monoblock spacer impossible. The mean Harris hip scores after a Girdlestone procedure have been reported at approximately 50, which is not as good as the scores for our concept [23, 25, 29, 31]. Moreover, an implanted spacer is advantageous because the local release of antibiotics from the cement takes part in effective treatment of the infection and implantation of a prosthesis during the second stage is technically much easier than after a Girdlestone procedure [10, 15]. Spacers prepared in the same way as described in the current study release antibiotics, even after 6 weeks, in amounts that are greater than the minimal inhibitory concentration for the bacteria that are causing the infection of the prosthesis bed [15].

The Harris hip scores assessed at the end of the 2-year followup with a mean of $82 \pm 16$ points were similar to those reported in other studies with one-stage revisions with mean scores between 77 and 84 and two-stage septic revisions with scores between 73.4 and 84.3 (Table 1) [5, 7-9, 17-19]. Citak et al. [8] calculated, in a literature review of 1631 two-stage revisions, a mean Harris hip score of 84.3 using a surgeon-made articulating spacer and 81.8 with a preformed hip spacer.

Because only one of our patients experienced a dislocation after the first operation, we believe this concept is effective in preventing instability in patients with acetabular defects.

The results of this pilot study show that this concept is a promising therapeutic option for periprosthetic infections of the hip in which major acetabular defects render the typical articulating-spacer approach risky, and where a two-stage procedure is preferred for treating the infection and managing the femoral side.

Acknowledgments We thank Lars Frommelt MD (Service for Infectious Diseases, Clinical Microbiology and Infection Control, ENDO-Klinik, Hamburg, Germany) for support in choosing local and systemic antibiotic therapy for patients included in this study and in writing this article.

\section{References}

1. Atkins BL, Athanasou N, Deeks JJ, Crook DW, Simpson H, Peto TE, McLardy-Smith P, Berendt AR. Prospective evaluation of criteria for microbiological diagnosis of prosthetic-joint infection at revision arthroplasty. J Clin Microbiol. 1998;36:2932-2939.

2. Böhm P, Bischel O. The use of tapered stems for femoral revision surgery. Clin Orthop Relat Res. 2004;420:148-159.

3. Bradford MS, Paprosky WG. Acetabular defect classification: a detailed radiographic approach. Semin Arthroplasty. 1995;6:7685 .

4. Burnett RS, Kelly MA, Hanssen AD, Barrack RL. Technique and timing of two-stage exchange for infection in TKA. Clin Orthop Relat Res. 2007;464:164-178.
5. Camurcu Y, Sofu H, Buyuk AF, Gursu S, Kaygusuz MA, Sahin V. Two-stage cementless revision total hip arthroplasty for infected primary hip arthroplasties. J Arthroplasty 2015;30:15791601.

6. Charlson ME, Pompel P, Ales KL, MacKenzie CR. A new method of classifying prognostic comorbidity in longitudinal studies: development and validation. $J$ Chronic Dis. 1987;40:373-383.

7. Choi HR, Kwon YM, Freiberg AA, Malchau H. Comparison of one-stage revision with antibiotic cement versus two-stage revision results for infected total hip arthroplasty. J Arthroplasty. 2013;28:66-70.

8. Citak M, Masri B, Springer B, Argenson JN, Kendoff DO. Are preformed articulating spacers superior to surgeon-made articulating spacers in the treatment of PJI in THA? A literature review. Open Orthop J. 2015;9:255-261.

9. De Man FH, Sendi P, Zimmerli W, Maurer TB, Ochsner PE, Ilchmann T. Infectiological, functional, and radiographic outcome after revision for prosthetic hip infection according to a strict algorithm: 22 one-stage and 50 two-stage revisions with a mean follow-up time of 5 (2-17) years. Acta Orthop. 2011;82:27-34.

10. Fink B. Revision of late periprosthetic infections of total hip endoprostheses: pros and cons of different concepts. Int J Med Sci. 2009;6:287-295

11. Fink B, Grossmann A. Modified transfemoral approach to revision arthroplasty with uncemented modular revision stems. Oper Orthop Traumatol. 2007;19:32-55.

12. Fink B, Grossmann A, Fuerst M, Schäfer P, Frommelt L. Twostage cementless revision of infected hip endoprostheses. Clin Orthop Relat Res. 2009;467:1848-1858.

13. Fink B, Grossmann A, Schubring S, Schulz MS, Fuerst M. A modified transfemoral approach using modular cementless revision stems. Clin Orthop Relat Res. 2007;462:105-114.

14. Fink B, Oremek D. The transfemoral approach for removal of well-fixed femoral stems in 2-stage septic hip revision. $J$ Arthroplasty. 2016;31:1065-1071.

15. Fink B, Vogt S, Reinsch M, Büchner H. Sufficient release of antibiotic by a spacer 6 weeks after implantation in two-stage revision of infected hip prostheses. Clin Orthop Relat Res. 2011;469:3141-3147.

16. Harris WH. Traumatic arthritis of the hip after dislocation and acetabular fractures: treatment by mold arthroplasty. An end result study using a new method of result evaluation. J Bone Joint Surg Am. 1969;51:737-755.

17. Hoberg M, Konrads C, Engelien J, Oschmann D, Holder M, Walcher M, Steinert A, Rudert M. Similar outcomes between two-stage revisions for infection and aseptic hip revisions. Int Orthop. 2016;40:459-464.

18. Ibrahim MS, Raja S, Khan MA, Haddad FS. A multidisciplinary team approach to two-stage revision for two-stage revision for the infected hip replacement: a minimum five-year follow-up study. Bone Joint J. 2014;96:1312-1318.

19. Ilchmann T, Zimmerli W, Ochsner PE, Kessler B, Zwicky L, Graber P, Clauss M. One-stage revision of infected hip arthroplasty: outcome of 39 consecutive hips. Int Orthop. 2016;40:913-918.

20. Klauser W, Bangert Y, Lubinus P, Kendoff D. Medium-term follow-up of a modular tapered noncemented titanium stem in revision total hip arthroplasty: a single-surgeon experience. $J$ Arthroplasty. 2013;28:84-89.

21. Kraay MJ, Goldberg VM, Fitzgerald SJ, Salata MJ. Cementless two-staged total hip arthroplasty for deep periprosthetic infection. Clin Orthop Relat Res. 2005;441:243-249.

22. Lange J, Troelsen A, Thomsen RW, Soballe K. Chronic infections in hip arthroplasties: comparing risk of reinfection 
following one-stage and two-stage revision: a systematic review and meta-analysis. Clin Epidemiol 2012;4:57-73.

23. Manjón-Cabeza Subirat JM, Moreno Palacios JA, Mozo Muriel AL, Cátedra Vallés E, Sancho Loras R, Ubeda Tikkanen A. Functional outcomes after resection of hip arthroplasty (Girdlestone technique). Rev Esp Geriatr Gerontol. 2008;43:13-18.

24. Masri BA, Panagiotopoulos KP, Greidanus NV, Garbuz DS, Duncan CP. Cementless two-stage exchange arthroplasty for infection after total hip arthroplasty. J Arthroplasty. 2007;22:72-78.

25. Oheim R, Gille J, Schoop R, Mägerlein S, Grimme CH, Jüregens C, Gerlach UJ. Surgical therapy of hip-joint empyema: is the Girdlestone arthroplasty still up to date? Int Orthop. 2012;36:927-933.

26. Pandey R, Drakouilakis E, Athanasou NA. An assessment of the histological criteria used to diagnose infection in hip revision arthroplasty tissues. J Clin Pathol. 1999;52:118-123.

27. Paprosky WG, Lawrence J, Cameron H. Femoral defect classification: clinical application. Orthop Rev.1990;19(suppl):9-15.

28. Parvizi J, Zmistowski B, Berbari EF, Bauer TW, Springer BD, Della Valle CJ, Garvin KL, Mont MA, Wongworawat MD, Zalavras CG. New definition of periprosthetic joint infection: from the Workgroup of the Musculoskeletal Infection Society. Clin Orthop Relat Res. 2011;469:2992-2994.

29. Scalvi A, Campacci A, Marcer M, Cassini M, Guerra C, Ferraresi M, Ghasemi MR. Girdlestone arthroplasty for loosening of the total hip prosthesis: evaluation and results. Chir Organi Mov. 1995;80:279-285.

30. Schäfer P, Fink B, Sandow D, Margull A, Berger I, Frommelt L. Prolonged bacterial culture to identify late periprosthetic joint infection: a promising strategy. Clin Infect Dis. 2008;47:14031409.

31. Schröder J, Saris D, Besselaar PP, Marti RK. Comparison of the results of the Girdlestone pseudarthrosis with reimplantation of a total hip replacement. Int Orthop. 1998;22:215-218.

32. Schuh A, Werber S, Holzwarth U, Zeiler G. Cementless modular hip revision arthroplasty using the MRP Titan Revision Stem: outcome of 79 hips after an average of 4 years' follow-up. Arch Orthop Trauma Surg. 2004;124:306-309.

33. Stockley I, Mockford BJ, Hoad-Reddick, Norman P. The use of two-stage exchange arthroplasty with depot antibiotics in the absence of long-term antibiotic therapy in infected total hip replacement. J Bone Joint Surg Br. 2008;90:145-148.

34. van Houwelingen AP, Duncan CP, Masri BA, Greidanus NV, Garbuz DS. High survival of modular tapered stems for proximal femoral bone defects at 5 to 10 years followup. Clin Orthop Relat Res. 2013;471:454-462.

35. Virolainen P, Lahteenmaki H, Hiltunen A, Sipola E, Meurman O, Nelimarkka $O$. The reliability of diagnosis of infection during revision arthroplasties. Scand J Surg. 2002;91:178-181.

36. Yoon BH, Ha YC, Lee YK, Koo KH. Postoperative deep infection after cemented versus cementless total hip arthroplasty: a meta-analysis. J Arthroplasty. 2015;30:1823-1827.

37. Zimmerli W, Widmer AF, Blatter M, Frei R, Ochsner PE. Role of rifampin for treatment of orthopedic implant-related staphylococcal infections: a randomized controlled trial. Foreign-Body Infection (FBI) Study Group. JAMA. 1998;279: $1537-1541$. 